EGU2020-9427

https://doi.org/10.5194/egusphere-egu2020-9427

EGU General Assembly 2020

(c) Author(s) 2022. This work is distributed under

the Creative Commons Attribution 4.0 License.

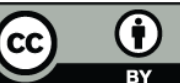

\title{
Temporal evolution of surface processes inferred from cosmogenic nuclides in a slow erosion setting, insights from the Sera do Cipo range, Brazil
}

\author{
Vincent Godard ${ }^{1}$, André Salgado ${ }^{2}$, Lionel Siame ${ }^{1}$, Jules Fleury ${ }^{1}$, and Team Aster ${ }^{1}$ \\ ${ }^{1}$ Aix-Marseille Univ, CNRS, IRD, INRA, Coll France, CEREGE, Aix-en-Provence, France \\ ${ }^{2}$ Department of Geography, Minas Gerais Federal University, Brazil
}

Understanding the degree of sensitivity of the Earth Surface to past climate changes is key to assess the strength of postulated links between weathering, denudation, rock uplift and climate. Numerous studies have investigated the response of surface processes to the evolution through time of temperature and precipitation, in various settings and over different time periods. In particular, an important question still actively debated concerns whether or not Late Cenozoic climate change had an effective impact on denudation rates. It is noteworthy that this Late Cenozoic climatic evolution is often described as a long-term cooling over several Ma. However, although it has been postulated to be an important control on this response, the impact of its orbitally-controlled high-frequency component has been less investigated.

Studies focusing on climate-denudation links have often been carried out in regions of high tectonic activity. Therefore, they encountered associated significant limitations, such as: (1) high denudation rates that reach the analytical limits of many measurement methods; (2) stochastic events introducing a high degree of variability in the denudation signal; and, (3) high rates of tectonic uplift that can limit the sensitivity to the low-frequency component of the climatic boundary condition. Less active tectonic settings with lower denudation rates may thus provide conditions allowing to focus specifically on the coupling between climate variations and surface processes. Additionally, approaches combining different cosmogenic nuclides have proven to be very effective to unravel changes in surface processes over several time scales.

We present a new cosmogenic nuclides dataset from the Sera do Cipo range in Minas Gerais, Brazil. The core of the range is made of resistant quarzite bedrock with a relief of $500 \mathrm{~m}$ with respect to the surrounding low lands, and reported denudation rates are $<10 \mathrm{~m} / \mathrm{Ma}$. Streams sediments from small catchments near the summit divide, as well as clasts derived from massive quartz veins at hilltop locations, were sampled. Both ${ }^{10} \mathrm{Be}$ and ${ }^{26} \mathrm{Al}$ concentrations were measured in the collected samples, as in such slow denudation settings the ratio between the two nuclides is sensitive to changes in denudation rates through time. A high-resolution $(1 \mathrm{~m})$ Digital Elevation Models was also produced from tri-stereo Pléiades satellite images. This allows to compute high resolution metrics such as hilltop curvature at the sampling sites. Hilltop denudation rates display a strong positive correlation with curvature. ${ }^{26} \mathrm{Al} /{ }^{10} \mathrm{Be}$ values significantly departing from the 
theoretical steady state denudation ratio are interpreted at hilltop sites as reflecting the fluctuation of denudation through time. Concerning the catchments samples, the determined ratio can also be impacted by the sediment transport history along hillslopes. Combining cosmogenic nuclides and high-resolution topographic datasets, the measured concentrations were inverted to constrain the variation of denudation over the last $2 \mathrm{Ma}$. We observe a significant change in the denudation regime at $1 \mathrm{Ma}$, with different kind of responses between ridges and small catchments across the landscape. 